\title{
Histological study of gonadal tissues of adult Artemia salina (Linnaeus 1758) and immunohistochemistry by Caspase 3 and HSP70 to detect specific apoptosis markers on gonadal tissues after exposure to TBTCI
}

\author{
Najla Mohamed Abushaala ${ }^{1 *}$, Abdulfattah Mohamed Elfituri ${ }^{2}$ and Syaizwan Zahmir Zulkifli ${ }^{3}$ \\ ${ }^{1}$ Zoology Department, Faculty of Science, University of Tripoli, Tripoli, Libya \\ ${ }^{2}$ Marine Biology Research Centre, Tajoura, Libya \\ ${ }^{3}$ Department of Biology, Faculty of Science, Universiti Putra Malaysia, 43400 UPM Serdang, Selangor, Malaysia
}

\begin{abstract}
Background: Several types of research have been recently carried out on the biological effects of TBTs, including investigations of genitals in invertebrates in response to exposure to TBTs in marine water.

Aim: The objective of this research was to investigate the acute effects of tributyltin chloride (TBTCl) on gonads in the adult stage of Artemia salina by use normal histology and immunohistochemistry (IHC) (Caspase 3 and HSP70) to see specific apoptosis markers.

Methods: After exposure of A. salina to different concentrations of $\operatorname{TBTCl}\left(25,50,100,200\right.$, and $\left.300 \mathrm{ng} .1^{-1}\right), 50$ adult A. salina ( 25 male and 25 female) were selected randomly from each concentration to histologically study the gonads. The gonad tissue was sectioned $(5 \mu \mathrm{m})$ and some slides were stained with hematoxylin and eosin and others were stained with IHC avidin-biotin complex, and were examined under a light microscope.

Results: The results showed significant differences $(p<0.05)$ in histological lesions between different concentrations of TBTCl. The histological lesions in the testis and ovary section were undifferentiated cells, degenerating yolk globules, and follicle cells enveloping the oocyte which was then compared with control tissue, and these effects were found to be increased in females more than in males with the highest concentration of TBTCl. Immunohistochemistry (IHC) showed that positive immunostaining was observed in the testis and ovary as brownish deposits to Caspase 3 and HSP70 antibody after exposure to TBTCl, while the testis and ovary section in control tissue had no immunoreactivity to Caspase 3 and HSP70 antibody; these effects were profoundly increased with the highest concentration of TBTCl in females more than in males. Finally, the histological lesions and IHC (Caspase 3 and HSP70) revealed that the apoptosis and immune system stress of $A$. salina gonad tissue damage in females were more sensitive to TBTCl toxicity as compared to white males.

Conclusion: In general, the present study aimed to observe the effects TBTCl on A. salina gonads by using histological sections and IHC (Caspase 3 and HSP70), which were evaluated for the first time and have been proven to possess an important function in apoptosis marker and immune system stress in Artemia. Finally, the specific mechanisms through which TBTCl affects $A$. salina Caspase 3 and HSP70 expression need further investigation.
\end{abstract}

Keywords: A. salina, Caspase 3, Ecotoxicology, Heat shock protein, Tributyltin chloride.

\section{Introduction}

The International Program on Chemical Safety (WHO, 2020) documented the presence of TBT at high levels in seawater, estuaries, freshwater, and sediments, as well as in aquatic organisms, such as bivalves, gastropods, and fishes. The levels of TBT in water as low as 2.0 ng. $1^{-1}$ have been reported to cause this effect (Alzieu et al., 1989). During 1977-1983, the oyster population in Arcachon Bay in France was severely affected by TBT contamination, which resulted in a reduction in oyster production because of increased mortality, decreased reproduction, and the presence of shell malformations. Ultimately, this led to substantial economic loss (Fent, 1996). This issue needs to be carefully investigated.
Tributyltin chloride (TBTCl) is used as an antifouling agent which prohibits the growth of organisms on ship hulls and has been in practice for many years. A large number of methods to preclude biofouling have been tested (Swain et al., 1998) and numerous electrical, chemical, thermal, and radiation techniques have been employed by these methods (Kiil et al., 2001). However, the chemically active antifouling paints have been most successful in fighting biofouling. The active ingredients of the antifouling paints are dispersed in a matrix from which they leach into the water (Kiil et al., 2001), thus forming a thin layer of highly concentrated biocides around the submerged surface and then the toxic concentration kills the organisms which are attached to the surface. 
There are many types of research using Artemia sp. to monitor spatial and temporal changes in the concentrations of TBTs (Ohji et al., 2002a; Abushaala et al., 2015, 2017, 2018, 2020; Abushaala, 2019). Nevertheless, only a few previous studies are available on the biological effects of TBTs on features such as growth, survival, reproduction, and the sex ratio of Artemia sp. Several studies have been recently carried out on the biological effects of TBT, including investigations into the reproduction and growth rate of caprellids species in response to the exposure of TBT in the ambient marine water (Ohji et al., 2003). It was found that the sex ratio dramatically changed after a brief exposure to TBT during the embryonic stage (Ohji et al., 2002b). However, the action mechanism of TBT can differ from one organism to another and the effects of its exposure may also vary according to the developmental stage.

The reproductive organ which forms the oocytes and sperm are among the important cells. They are used to evaluate the fertility potential of individuals. Infertility and the production of defective gametes may happen because of the failure of germ cells to survive (Modi et al., 2003). Billig et al. (1996) provided evidence that cell apoptosis plays an important role in the normal functioning of tissues. A healthy person will have balanced cell apoptosis and proliferation. Furthermore, Billig et al. (1996) underscored that gonadotrophins serve as survival factors, in both the testis and ovary. In line with this, Raff (1992) argued that in order for the individual to maintain a homeostatic state, the potential for cell suicide appears to be existing in most of the tissues. Death of the apoptotic cells can be diagnosed via morphological changes: membrane blebbing, disruption of the skeleton of the cell, shrinkage of cells, condensation of nuclear acids, disruption of cells into small membrane enclosed fragments known as apoptosis bodies, and phagocytosis by nearby cells to complete degradation of the cell (Billig et al., 1996). The aim of this research is to study the effects of TBTCl on the histological changes of genital organs of male and female Artemia salina, and to see the apoptosis marker and immune system stress on the histological tissues and compare the effects between males and females using Caspase 3 and heat shock protein 70 (HSP70). The results of this study will be important for the discussion of the fluctuation in abundance of marine species in the ecosystem, as well as the biological impacts of TBTCl on marine organisms.

\section{Materials and Methods}

Dilutions of the TBTCl series' concentrations were 25, $50,100,200$, and $300 \mathrm{ng} \cdot \mathrm{l}^{-1}$ in order to study the effects of TBTCl on gonads of $A$. salina in acute toxicity testing. This range was determined based on previous studies (Abushaala, 2019).

\section{Test organisms}

Culturing of A. salina was conducted for hatching approximately $0.5 \mathrm{~g}$ of cysts, in a 51 bottle of artificial seawater having $35 \%$ $\pm 1 \%$ salinity at $28^{\circ} \mathrm{C} \pm 1^{\circ} \mathrm{C}$ for 24 hours under standardized hatching conditions. The feeding capability of $A$. salina was fully developed after 24 hours. Once the feeding capability was reached, food levels were established based on marine green microalgae Tetrasalims sp., a single cell organism dominant from the Marine Science LAB, Institute of Bioscience, University Putra Malaysia, and cultured in the Ecotoxicology Laboratory, Department of Biology, University Putra Malaysia. Then, $1 \mathrm{ml}$ of commercial liquid food suspension was added per liter to aquaculture containers every day to provide other food. The inoculation with this food mixture was used for 3 days. Feed application was just enough to cloud the water so that the following application could be done when the water was clear. The application was performed at least twice daily. Identical food concentrations were fed in each growth container. During this period and for the following days, the animals were reared in the laboratory using the same apparatus and conditions. Water was continuously aerated by air stones connected to airline water pumps and the dissolved oxygen was always higher than 7.0 mg. $1^{-1}$. The photoperiod was put in place continuously for illumination purposes using a fluorescent light tube of $60 \mathrm{~W}$. Also, precipitated material (remaining food and dead shrimps) was siphoned out. This procedure prevented ammonia from attaining higher values. After 3 days, the live food was replaced gradually with the food recommended by Toi et al. (2013). Adult $A$. salina were transferred to new artificial seawater before the toxicity test by using the YSI Model 58 Dissolved Oxygen Meter (Yellow Springs Instrument Co. Inc., Yellow Springs, $\mathrm{OH}$ ) in the laboratory for measurement purposes (DO $8.0 \pm 0.5$ mg. $.^{-1}, \mathrm{pH} 7.5-8.0$ and artificial seawater 35\%o $\pm 1 \%$ ). Artificial seawater was prepared by mixing commercial salts with distilled water and ventilation was carried out for 24 hours to be used either for culture procedure or toxicity solution (Toi et al., 2013).

Effect of $\mathrm{TBTCl}$ on reproductive gonads of male and female tissue staining with hematoxylin and eosin

Histological analysis of reproductive gonad tissue was carried out on 50 samples of $A$. salina selected randomly from each group ( 25 male and 25 female), and were fixed with Bouin's solution for 24 hours. After that, preparation for histological sections was made for the tissue to be cut into $5 \mu \mathrm{m}$ thickness. Finally, they were stained with hematoxylin and eosin, following Abushaala's (2019) method. All the tissue sections were observed under a light microscope connected to a computer and a camera to measure the scores of gonad structure affected by TBTCl.

\section{Experimental design of IHC}

Caspase 3 and HSP70 responses in the $A$. salina when exposed to TBTCl

The Caspase 3 and HSP70 response in the A. salina exposed to different concentrations of TBTCl was investigated. In the adult stage experiments (of females and males), they were exposed to $25,50,100,200$, 
and 300 ng. $1^{-1}$ in acute toxicity test for 24 hours. In the histological experiments, A. salina was put in Bouin's solution for 24 hours preparing for the histology section. The Caspase 3 and HSP70 expressions were determined after the tissue was sectioned (Cruz-Rodriguez and Chu, 2002; Klepal et al., 2008; Abushaala, 2019). IHC avidin-biotin complex (ABC) was used in this study following the $\mathrm{ABC}$ stinging system sc-2017 kit (Santa Cruz Biotechnology, Inc.).

\section{Statistical analysis}

The statistical analysis for histological study after observing acute toxicity effects of TBTCl on gonads of $A$. salina using means and $\mathrm{SE}$ of score system assessing histological effects of TBTCl in the gonad structures of adult stages of males and females, and the scoring methods for pathological lesions were normal $(0)$, mild $(<25)$, moderate $(<50)$, severe $(<75)$, and very severe (above 75). For IHC study, Caspase 3 and HSP70 on the gonad structure of males and females using the immunostaining scores for Caspase 3 and HSP70 were normal $(0)$, mild $(<5)$, moderate $(<10)$, and severe (up to 20), and the immunostaining was observed as brownish deposits. The statistical analysis was carrie dout using Kruskal-Wallis test $(p<0.05)$, and differences were considered significant at $p<$ 0.05 , observing the relationship between the effect of different concentrations of (TBTCl) on gonad structures in A. salina males and females.

\section{Ethical approval}

No ethical approval was needed for this research work.

\section{Results}

Effects of TBTCl on gonadal tissues of male and female A. salina stained with hematoxylin and eosin

The result from the testis section of males (Fig. 1) shows that in the predominant lesions undifferentiated cells and degenerating testicular tissue were significantly different, and the results also showed a $p$-value $<0.05$ between the different concentrations, according to Kruskal-Wallis test. The result of female $A$. salina gonad exposed to $\mathrm{TBTCl}$ is shown in Figure 2. The lesion scores at different concentrations were significantly different from each other at different concentrations showing undifferentiated cells in the head region, vitellogenic oocyte with degenerating yolk globules in the ooplasm, and degenerating yolk globules and follicle cells enveloping the oocyte increasing these effects in the groups exposed to the highest concentration when compared with control tissues (Table 1).

Immunostaining scores of Caspase 3 antibody on gonads of male and female A. salina tissues after exposure to $\mathrm{TBTCl}$

The mean immunostaining scores of Caspase 3 in adult males are shown in Table 2. The concentrations of TBTCl in this group were $0,25,50,100,200$, and $300 \mathrm{ng} . \mathrm{l}^{-1}$, respectively, and the tissues stained were from the testis. Positive immunostaining was observed as brownish deposits, indicating the location of the Caspase 3 antigen-antibody reaction. There were no significant differences between the groups. In the testis of the adult male $A$. salina, the least immunostaining score of $8.00 \pm 0.09$ was recorded at the exposure concentration of $25 \mathrm{ng} . \mathrm{l}^{-1}$ of $\mathrm{TBTCl}$, while the highest was obtained at the exposure concentration of 200 ng. $1^{-1}$ of TBTCl. However, the test recorded the lowest immune score in the male $A$. salina as compared to the gonads in females, which was higher than that in the testis. The effect of immunostaining scores of Caspase 3 on males tissue is shown in Figure 3. The results of immunostaining scores for female A. salina to different concentrations of TBTCl is shown in Figure 4. Positive immunostaining was observed as brownish deposits, indicating the location of the Caspase 3 antigen-antibody reaction, and there were significant differences according to Kruskal-Wallis test, where significant $p$-values of $<0.05$ between 25 and $50 \mathrm{ng} .1^{-1}$,
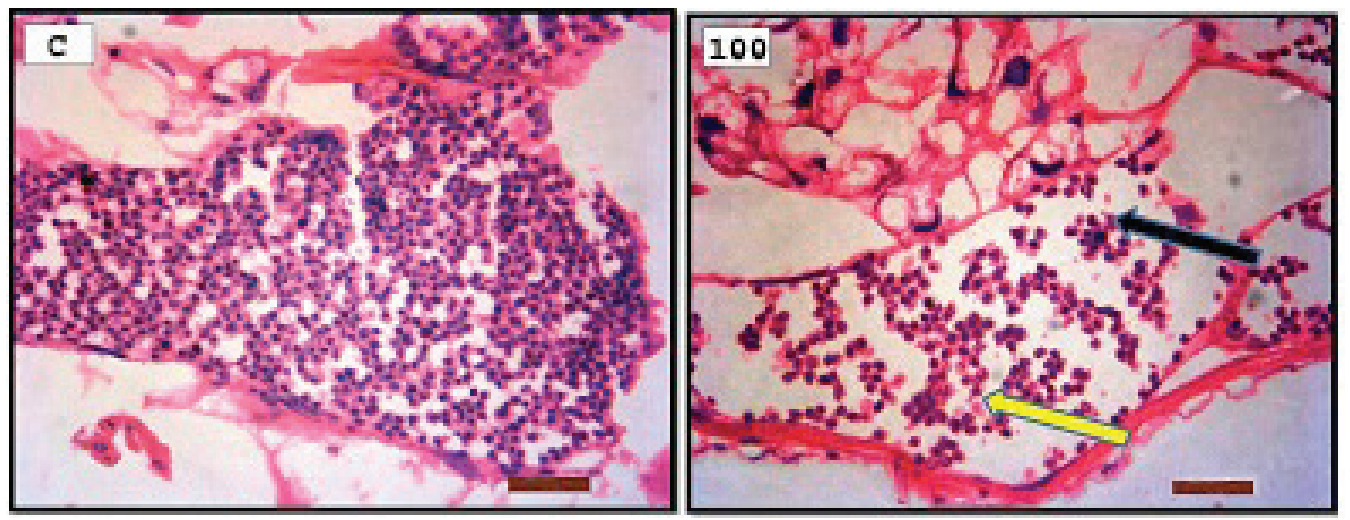

Fig. 1. Representative photomicrograph of a section of male testis with a normal histological structure (C: left), and on the right the histological changes are shown following 24-hours exposure to TBTCl at $100 \mathrm{ng} .1^{-1}$ concentration, which are shown as undifferentiated cells (black arrow) and degenerating testis tissue (yellow arrow) compared with the control tissue $(\mathrm{H} \& \mathrm{E}, \times 40)$. 

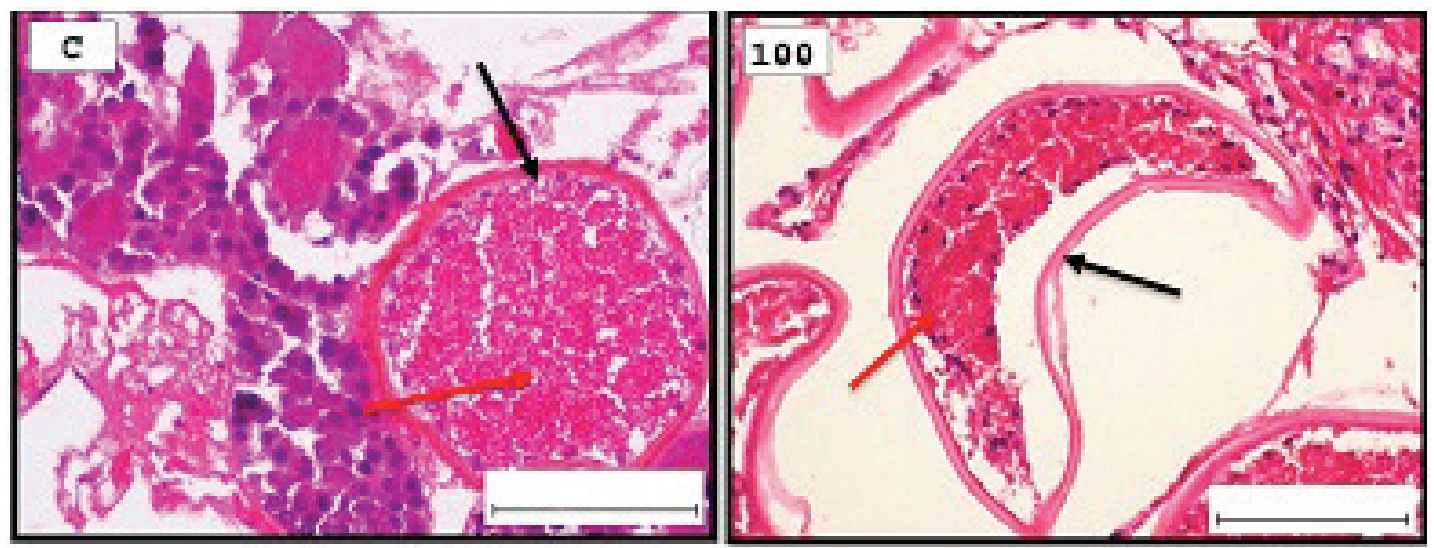

Fig. 2. Representative photomicrograph of a section of female ovary of A. salina with a normal histological structure of the control showing vitellogeninoocyte (black arrow), yolk globules in the ooplasm (red arrow) (C: on the left), and on the right the histological changes are shown following 24-hours exposure to TBTCl at 100 ng. $1^{-1}$ concentration, which are shown as follicle cells enveloping the oocyte (black arrow) and degenerating yolk globules (red arrow) $(\mathrm{H} \& \mathrm{E}, \times 40)$.

Table 1. Hematoxylin and eosin mean scores on the effect TBTCl on gonad structure in adult male and female $A$. salina $(\mathrm{n}=5$ slides $)$.

\begin{tabular}{ccc}
\hline TBTCl $\left(\right.$ ng. $\left.^{-1}{ }^{-1}\right)$ & Testis & Ovary \\
\hline 0 & $0.00 \pm 0.00$ & $0.00 \pm 0.00$ \\
25 & $2.20 \pm 0.90$ & $2.60 \pm 0.09$ \\
50 & $2.40 \pm 1.00$ & $2.40 \pm 1.00$ \\
100 & $2.80 \pm 0.60$ & $3.00 \pm 0.99$ \\
200 & $3.00 \pm 0.99$ & $3.00 \pm 0.99$ \\
300 & $3.00 \pm 0.99$ & $3.00 \pm 0.99$ \\
\hline
\end{tabular}

Scoring methods: 0: Normal; 1-5: Mild; 5-10: Moderate; and up to 10: Severe. All data are presented with \pm SE.
Table 2. Immunostaining scores of Caspase 3 antibody after the effects of TBTCl on gonad tructure of male and female A. salina $(n=5$, five fields/slide).

\begin{tabular}{ccc}
\hline TBTCl (ng. $^{-\mathbf{1}}$ ) & Testis & Ovary \\
\hline 0 & $0.00 \pm 0.00$ & $0.00 \pm 0.00$ \\
25 & $8.00 \pm 0.09$ & $11.8 \pm 0.78$ \\
50 & $10.0 \pm 0.69$ & $19.4 \pm 1.58$ \\
100 & $11.2 \pm 0.29$ & $19.6 \pm 1.60$ \\
200 & $12.2 \pm 1.50$ & $22.0 \pm 1.64$ \\
300 & $9.00 \pm 1.39$ & $19.4 \pm 1.58$ \\
\hline
\end{tabular}

Scoring methods: 0 : Normal; $<5$ : Mild; $<10$ : Moderate; and up to 20: Severe. All data are presented with \pm SE.

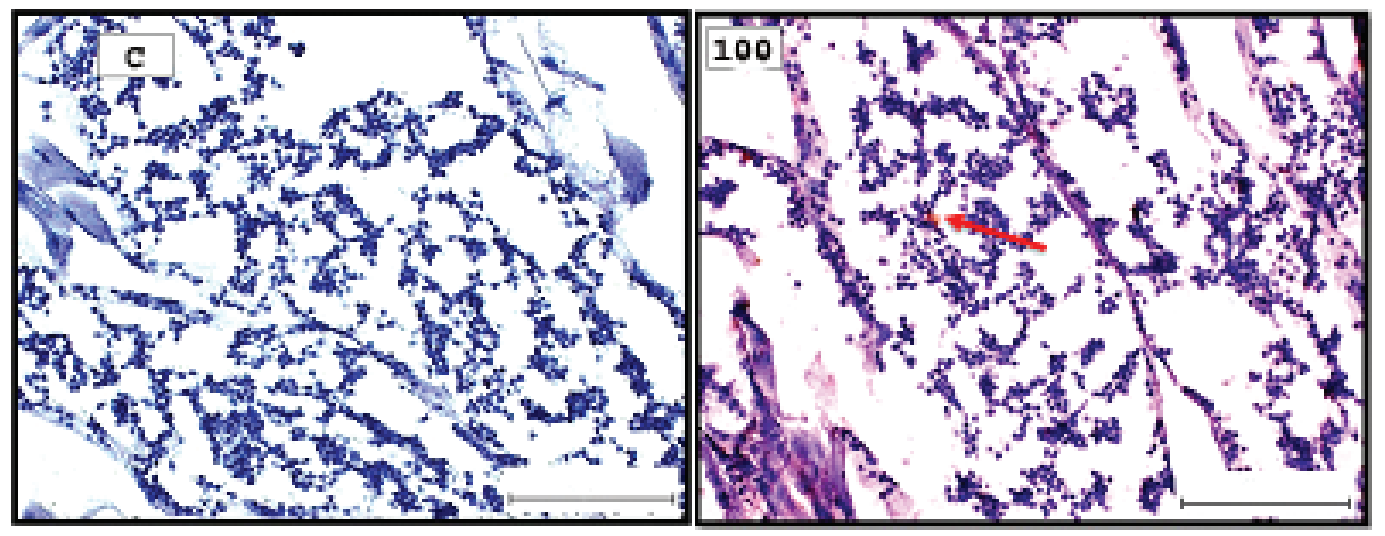

Fig. 3. Representative photomicrograph of a section of male testis of $A$. salina of the control (C: on the left) showing no immunoreactivity to Caspase 3 antibody, and at $100 \mathrm{ng} \cdot \mathrm{l}^{-1}$ of TBTCl concentration showing mild immunoreactivity to Caspase 3 antibody (on the right). Positive immunostaining was observed as brownish deposits $(\mathrm{H} \& \mathrm{E}, \times 40)$. 

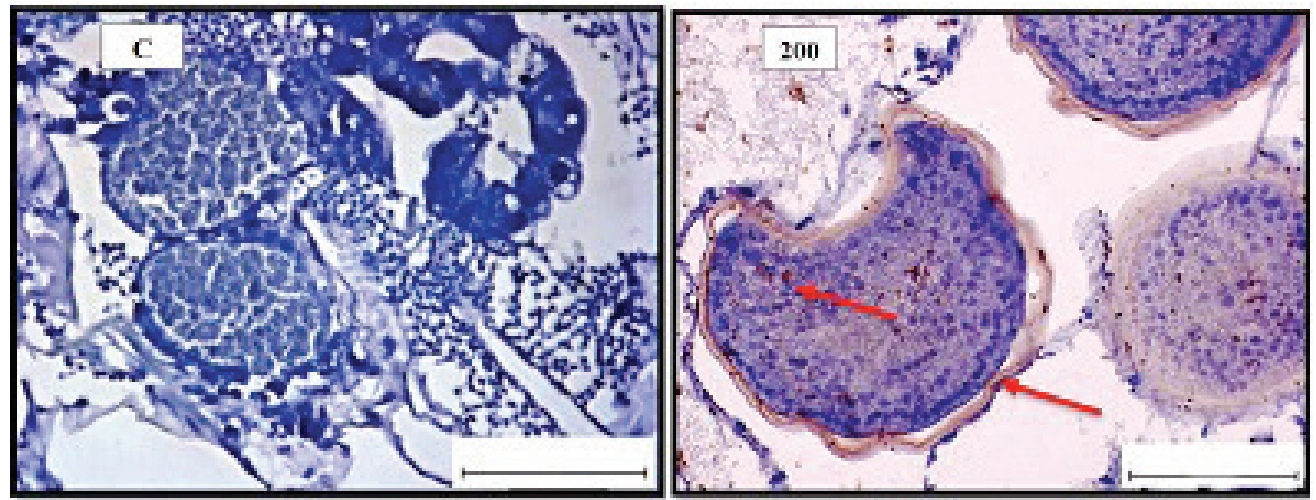

Fig. 4. Representative photomicrograph of a section of female ovary of A. salina of the control (C: on the left) showing no immunoreactivity to Caspase 3 antibody, and at $200 \mathrm{ng} . \mathrm{l}^{-1}$ concentration showing moderate immunoreactivity to Caspase 3 antibody, following 24-hours exposure to TBTCl (on the right) and the positive immunostaining was observed as brownish deposits $(\mathrm{H} \& \mathrm{E}, \times 40)$.

25 and 100 ng. $.^{-1}, 25$ and 300 ng. $1^{-1}$, and between 200 and 300 ng..$^{-1}$ exposure groups were observed. The least immunostaining score $(11.8 \pm 0.29)$ for Caspase 3 in the gonads was obtained from an exposure concentration of $25 \mathrm{ng} . \mathrm{l}^{-1}$ of TBTCl, while the highest score of $22.0 \pm 0.29$ was obtained at the concentration of 200 ng. $1^{-1}$ TBTCl (Table 2).

Immunostaining scores of HSP70 for male and female A. salina gonad tissues upon exposure to TBTCl

The findings of immunostaining scores of HSP70 after 24-hours exposure of males $A$. salina to different concentrations of TBTCl is shown in Table 3. Positive immunostaining was observed as brownish deposits, indicating the location of the HSP70 antigen-antibody reaction. Significant differences were observed between 25 and 100 ng. $1^{-1}, 50$ and 100 ng. $1^{-1}$, and between 100 and 300 ng. $\mathrm{l}^{-1}$ exposure groups. In male $A$. salina, the HSP70 immunostaining score was highest at 300 ng. $\mathrm{l}^{-1}$ of TBTCl. The generality of the immunostaining score of the HSP70 in males A. salina showed that the testis had the highest immunostaining scores, as shown in Figure 5. The mean immunostaining scores of HSP70 in female A. salina is shown in Table 3 and Figure 6. The positive immunostaining was observed as brownish deposits, indicating the location of the HSP70 antigenantibody reaction on the ovary. There was a significant difference between 25 and 200 ng. $\mathrm{l}^{-1}, 25$ and 300 ng. $^{-1}$, and between 50 and 300 ng..$^{-1}$ exposure groups. The HSP70 immunostaining score for female $A$. salina was low $(20.0 \pm 1.90)$ at the exposure concentration of 25 ng. $l^{-1} \mathrm{TBTCl}$ and the highest immunostaining in the gonads was obtained at the exposure concentration of 300 ng. $1^{-1}$ of TBTCl.

\section{Discussion}

Effects of TBTCl on gonad tissues of male and female A. salina stained with hematoxylin and eosin

The mean lesion scores post-24-hours exposure of male A. salina to different concentrations of TBTCl
Table 3. Immunostaining scores of HSP70 on gonad structure of tissues exposed to TBTCl of male and female $A$. salina $(n=5$, five fields/slide).

\begin{tabular}{ccc}
\hline TBTCl $\left(\right.$ ng. $\left.^{-\mathbf{1}}\right)$ & Testis & Ovary \\
\hline 0 & $0.00 \pm 0.00$ & $0.00 \pm 0.00$ \\
25 & $9.40 \pm 0.90$ & $20.0 \pm 1.90$ \\
50 & $7.20 \pm 0.49$ & $18.6 \pm 2.38$ \\
100 & $11.2 \pm 0.29$ & $20.0 \pm 1.89$ \\
200 & $10.8 \pm 0.49$ & $22.8 \pm 1.58$ \\
300 & $12.2 \pm 1.50$ & $24.8 \pm 2.79$ \\
\hline
\end{tabular}

Scoring methods: 0:Normal; $<5$ : Mild; $<10$ : Moderate; and up to 20: Severe. All data are presented with \pm SE.

is shown in Figure 1. The results showed that the predominant lesions such as undifferentiated cells and degenerating testicular tissue were significantly different, according to Kruskal-Wallis test $(p<0.05)$ between the groups. These effects were observed to increase testicular tissues that were exposed to the highest concentration of TBTCl when compared with control tissues. Artemia salina female gonads exposed to different concentrations of TBTCl is shown in Figure 2. The lesion scores at the different concentration were significantly different from each other showing undifferentiated cells in the head region, vitellogenic oocyte with degenerating yolk globules in the ooplasm, and degenerating yolk globules and follicle cells enveloping the oocyte increasing these effects in the groups exposed to the highest concentration when compared with control tissues (Table 1). Zhang et al. (2007) studied the effect of tributyltin and found that TBT could induce masculinization in marine invertebrates. Their study was conducted to investigate the effects of TBT in environmental marine water on the development of ovaries in females. The result reported that TBT at environmentally realistic concentrations 


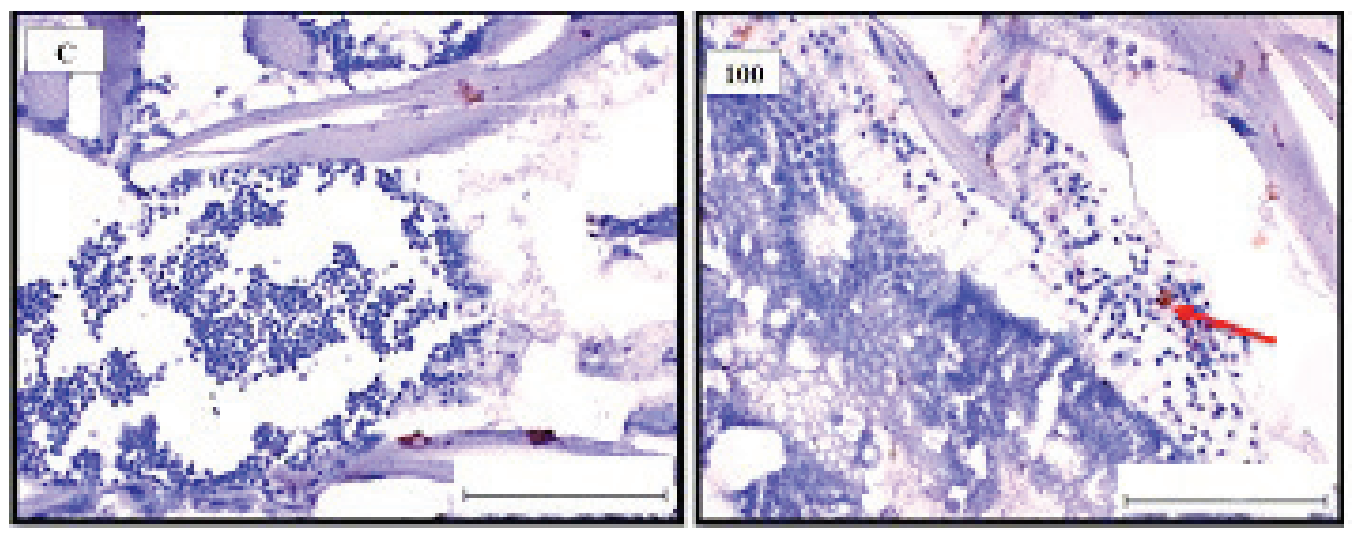

Fig. 5. Representative photomicrograph of a section of male testis of $A$. salina of the control (C: on the left) showing no immunoreactivity to HSP70 antibody, and at $100 \mathrm{ng} \cdot \mathrm{l}^{-1}$ showing mild immunoreactivity to HSP70 antibody, following 24-hours exposure to concentrated TBTCl (on the right). Positive immunostaining was observed as brownish deposits $(\mathrm{H} \& \mathrm{E}, \times 40)$.
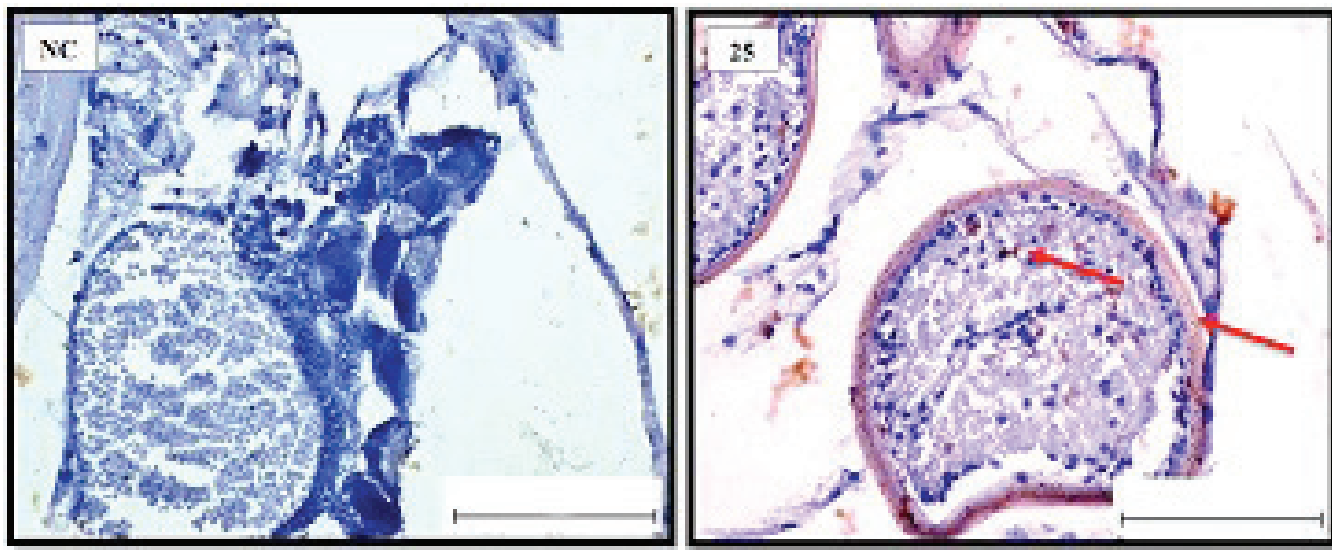

Fig. 6. Representative photomicrograph of a section of female ovary of A. salina showing normal immunoreactivity to HSP70 antibody in the control (C: on the left), and at $25 \mathrm{ng} \cdot \mathrm{l}^{-1}$ concentration showing moderate immunoreactivity to HSP70 antibody following 24-hour exposure to TBTCl (on the right). Positive immunostaining was observed as brownish deposits (H\&E, $\times 40)$.

could inhibit the ovarian development in fish. And the few previous studies reported the effect of TBT in fish and crustaceans. In the present research, the effects of TBTCl at different concentrations on the ovary in female and testis in male $A$. salina was investigated. Analysis of the data obtained from our study has shown that TBTCl at environmentally realistic concentrations can inhibit the development of the reproductive gonad in A. salina at varying degrees depending on the concentration of TBTCl. This finding is in relative agreement with previous related studies where TBTCl was reported to be highly toxic against several aquatic organisms (Zuo et al., 2014). This finding is indeed interesting because Artemia is commonly used to represent the biotic populations of many aquatic environments (Ohji et al., 2002a) and any chemical that is found to be detrimental to Artemia is likely to be detrimental to several other aquatic organisms.
Immunostaining scores of Caspase 3 antibody on gonad of male and female A. salina tissues after exposure to TBTCl

Caspase 3 has been demonstrated to possess important functions in apoptosis and immune system of vertebrates. The mean immunostaining scores of Caspase 3; 24-hours after exposure of adult male A. salina to different concentrations of $\mathrm{TBTCl}$ are shown in Table 2. The concentrations of the TBTCl in this group were $0,25,50,100,200$ and $300 \mathrm{ng} .1^{-1}$, respectively, and the tissues stained was from the testis. Positive immunostaining was observed as brownish deposits, indicating the location of the Caspase 3 antigen-antibody reaction. There were no significant differences between the groups. In the testis of the adult male $A$. salina, the least immunostaining score of $8.00 \pm 0.09$ was recorded at the exposure concentration of $25 \mathrm{ng} . \mathrm{l}^{-1}$ of TBTCl while the highest was obtained 
at the exposure concentration of 200 ng..$^{-1}$ of TBTCl. However, the test has recorded the lowest immune score in the male A. salina as compared to the gonad in the female, which was higher than the testis. The effect of immunostaining scores of Caspase 3 on male tissue has been depicted in (Fig. 3). The results of immunostaining scores for Caspase 3 after 24 hours exposure of females A. salina to different concentrations of $\mathrm{TBTCl}$ is shown in (Fig. 4). The positive immunostaining was observed as brownish deposits, indicating the location of the Caspase 3 antigen-antibody reaction, and there were significant differences according to Kruskal-Wallis test which showed a significant difference $(p<0.05)$ between 25 and 50 ng. $1^{-1}, 25$ and 100 ng. $1^{-1}, 25$ and 300 ng. $\mathrm{l}^{-1}$, and between 200 and $300 \mathrm{ng} . \mathrm{l}^{-1}$ exposure groups. The least immunostaining score $(11.8 \pm 0.29)$ for Caspase 3 in the gonad was obtained from an exposure concentration of $25 \mathrm{ng} . \mathrm{l}^{-1}$ of TBTCl, while the highest score of $22.0 \pm 0.29$ was obtained at the concentration of $200 \mathrm{ng} \cdot \mathrm{l}^{-1}$ of TBTCl (Table 2). Generally, the gonad of the adult female $A$. salina had the highest immune scores as compared to the male organs. But there is less information reported on A. salina ovary and testis development with respect to caspase. In the present research, the effects of different concentrations of TBTCl on A. salina gonad Caspase 3 were evaluated for the first time. Yang et al. (2015) studied caspase genes on molluscan, named Caspase 2 and 3, which were characterized for the first time from Crassostrea angulata. The analysis of their data showed that the Caspase 3 gene has an important function in the loss of velum during larva metamorphosis in C. angulata. In this study, Caspase 3 was found to be influenced by the different concentrations of TBTCl following 24 hours exposure of $A$. salina. The specific mechanisms through which $\mathrm{TBTCl}$ exposure affects $A$. salina Caspase 3 expression need further investigation.

Immunostaining scores of HSP70 for male and female A. salina gonad tissues upon exposure to TBTCl

The findings of immunostaining scores of HSP70 after 24-hours exposure of male A. salina to different concentrations of TBTCl is shown in Table 3. Positive immunostaining was observed as brownish deposits, indicating the location of the HSP70 antigen-antibody reaction. Significant differences were observed between 25 and 100 ng. $1^{-1}, 50$ and 100 ng. $1^{-1}$, and between 100 and $300 \mathrm{ng} . \mathrm{l}^{-1}$ exposure groups. In male A. salina, HSP70 immunostaining score was highest at $300 \mathrm{ng} . \mathrm{l}^{-1}$ of TBTCl. The generality of the immunostaining score of the HSP70 in male A. salina showed the testis to have the highest immunostaining scores as shown in Figure 5. The mean immunostaining scores of HSP70 in female A. salina is shown in Table 3 and Figure 6. The positive immunostaining was observed as brownish deposits, indicating the location of the HSP70 antigen-antibody reaction on the ovary. There was a significant difference between 25 and 200, 25 and 300 ng. $\mathrm{l}^{-1}$, and between 50 and 300 ng. $\mathrm{l}^{-1}$ exposure groups.
The HSP70 immunostaining score for females $A$. salina was low $(20.0 \pm 1.90)$ at the exposure concentration of $25 \mathrm{ng} . \mathrm{l}^{-1}$ of TBTCl and the highest immunostaining in the gonads was obtained at the exposure concentration of $300 \mathrm{ng} . \mathrm{l}^{-1}$ of TBTCl. Wang et al. (2012) reported that Artemia embryos can endure extreme temperature and other wide variety of stressful environmental conditions. And the embryos can survive these stresses is highly interesting. Wang et al. (2012) investigated and analyzed the nucleotide and deduced protein sequence for HSP26, a molecular chaperone specific to Artemia embryo development. HSP26 shares sequence similarity with sHSPs (small HSP) from other organisms. The authors (Wang et al., 2012) observed that HSP26 plays a key role in the resistance of Artemia against harsh environmental conditions. Findings from the study by Zhou et al. (2010) were used to reveal the differential protein expression profiles of acute responses to copper sulfate exposure in larvae of Artemia sinica. Three spots were up-regulated and identified as actin, HSP70. The study indicated the involvement of all the differentially expressed proteins in the early responses of protein expression, and in the survival of $A$. sinica in the presence of copper and other heavy metals.

In this study, exposure of $A$. salina to different concentrations of TBTCl was found to have a significant influence on HSP70 expression. An inverse relationship was found between HSP70 expression and TBTCl concentrations. This shows that exposure of $A$. salina to TBTCl significantly influences the ability of $A$. salina to express HSP70, which could have contributed to the mortality and histopathological changes observed in this study. Tanguay et al. (2004) studied cysts embryos of the Artemia sp. Which provided excellent opportunity for the study to understand how these marine organisms adapt to extremes of environmental stress. One adaptation implicated in the ecological success of Artemia sp. is sHSP26, a small HSP that previous evidence indicates plays the role of a molecular chaperone in the embryos. The findings found the contents of three stress proteins (HSP70, Artemin and sHSP26) presented along with data on the cysts of A. tibetana collected from the high plateau of Tibet.

TBTCl is one of the potentially significant sources of pollutants, in the marine environment. The results showed, according to Kruskal-Wallis test $p<0.05$ a significant increase in HSP70 levels when A. salina was exposed to higher concentrations 25, 50, 100, 200 and $300 \mathrm{ng} . \mathrm{l}^{-1}$. Groups exposed to 100,200 and $300 \mathrm{ng} . \mathrm{l}^{-1}$ of TBTCl were found to significantly express higher levels of HSP70, with those exposed to 25, $50 \mathrm{ng} \cdot .^{-1}$ TBTCl expressing the highest levels of HSP70. This finding corroborates with the findings of Zhou et al. (2010), who similarly reported that exposure of Artemia to TBTCl significantly influenced the expression of HSP70. Other related studies have similarly reported 
the effects of TBTCl on different species in the aquatic environment (Gallo and Tosti, 2015).

\section{Conclusion}

In the present study, the effects of TBTCl on adult gonad of $A$. salina by using histological sections were onbserved, and IHC (Caspase 3 and HSP70) has been evaluated for the first time on Artemia. The testis tissue shows pathological lesions after exposure to TBTCl as undifferentiated cells and degenerating testis tissue when compare with the control tissue. In the female's ovaries, the lesion scores at different concentrations are significantly different from each other showing undifferentiated cells of the vitellogenic oocyte with degenerating yolk globules in the ooplasm, and degenerating yolk globules and follicle cells enveloping the oocyte increasing these effects in the groups exposed to the highest concentrations when compared with control tissue. In general, histological lesion and IHC (Caspase 3 and HSP70) revealed the apoptosis and immune system stress of gonad tissue of A. salina to be damaged in females which are more sensitive to TBTCl toxicity as compared to white males that have been exposed to TBTCl contaminated water. This study reconfirms the suitability of the A. salina for assessing the marine aquatic toxicity profile of any toxicant with simple and reproducible results. Finally, the specific mechanisms through which TBTCl affects $A$. salina Caspase 3 and HSP70 expression need further investigation.

\section{Acknowledgments}

We are grateful to the Department of Biology, Faculty of Science, University Putra Malaysia, and to the Unit of Histology and Serology Faculty of Veterinary, University Putra Malaysia (UPM) for providing facilities and equipment for this investigation.

\section{Authors' contribution}

Najla Mohamed Abushaala conducted experiments, analyzed, and wrote the manuscripts. Abdulfattah Elfituri contributed to the experiences that have a relationship with the development of Artemia salina (Agriculture microalgae to feed Artemia). Syaizwan Zahmir Zulkifli supervised the project and supported it financially (by providing facilities and equipment for this investigation).

\section{References}

Abushaala, N.M. 2019. Effects of tributyltin chloride on cell structures of epithelial layer in different stages of Artemia salina (Linnaeus, 1758). Open Vet. J. 9, 366-374.

Abushaala, N.M., Zulkifli, S.Z., Ismail, A. and Elftturi, A.M. 2020. Hatchability dry cysts and morphological effects of newly hatching nauplii of Artemia Salina (Linnaeus, 1758) after exposed to tributyltin chloride. Global J. Med. Res. 20(3), $33-42$.
Abushaala, N.M., Zulkifli, S.Z., Ismail, A., Azmai, M.N.A. and Mohamat-Yusuff, F. 2015. Selected morphological changes in nauplii of brine shrimp (Artemia salina) after tributyltin chloride (TBTCl) exposure. World Appl. Sci. J. 33(8), 1334-1340.

Abushaala, N.M., Zulkifli, S.Z., Ismail, A., Azmai, M.N.A., Mohamat-Yusuff, F. and Omar, H. 2017. Effects of tributyltin chloride (TBTCl) antifouliong biocide on adult males and females of brine shrimp (Artemia salina). Int. J. Biol. Res. 5(1), 30-35.

Abushaala, N.M., Zulkifli, S.Z., Ismail, A., Azmai, M.N.A., Mohamat-Yusuff, F. and Omar, H. 2018. Biological effects of tributyltin chloride (TBTCl) on Juveniles Stage of Life cycle Artemia salina. Available via www.science.upm.edu.my/ ebook-3213

Alzieu, C., Sanjuan, J., Michel, P., Borel, M. and Dreno, J. 1989. Monitoring and assessement of butyltins in Atlantic coastal waters. Mar. Pollu. Bull. 20(1), 22-26.

Asaadi, S.N., Pousty, I. and Khah, D.A. 2015. Histological evaluation of the genital tract of Artemia parthenogenetica in Urmia Lake Area. European Online J. Nat. Soc. Sci. 4(1), 91.

Asem, A. and Rastegar-Pouyani, N. (2008). Morphological differentiation of Artemia urmiana Günther, 1899 (Crustacea: Anostraca) in different geographical stations from the Urmia Lake-Iran. Res. J. Biol. Sci. 3(2), 222-228.

Billig, H., Chun, S.-Y., Eisenhauer, K. and Hsueh, A. J. (1996). Gonadal cell apoptosis: hormone-regulated cell demise. Hum. Reprod. Update. 2(2), 103-117.

Cruz-Rodriguez, L.A. and Chu, F.-L.E. 2002. Heatshock protein (HSP70) response in the eastern oyster, Crassostrea virginica, exposed to PAHs sorbed to suspended artificial clay particles and to suspended field contaminated sediments. Aquat. Toxicol. 60(3), 157-168.

Fent, K. 1996. Ecotoxicology of organotin compounds. Crit. Rev. Toxicol. 26(1), 1-117.

Gallo, A. and Tosti, E. 2015. The ascidian Ciona intestinalis as model organism for ecotoxicological bioassays. J. Mar. Sci. Res. Devel. 5(3), 000e138.

Kiil, S., Weinell, C.E., Pedersen, M.S. and DamJohansen, K. 2001. Analysis of self polishing antifouling paints using rotary experiments and mathematical modeling. Ind. Eng. Chem. Res. 40(18), 3906-3920.

Klepal, W., Gruber, D. and Pflugfelder, B. 2008. Natural cyclic degeneration by a sequence of programmed cell death modes in Semibalanus balanoides (Linnaeus, 1767) (Crustacea, Cirripedia Thoracica). Zoomorph. 127(1), 49-58.

Modi, D., Sane, S. and Bhartiya, D. 2003. Accelerated germ cell apoptosis in sex chromosome aneuploid fetal human gonads. Mol. Hum. Reprod. 9(4), 219225. 
Ohji, M., Arai, T. and Miyazaki, N. 2002a. Effects of tributyltin exposure in the embryonic stage on sex ratio and survival rate in the caprellid amphipod Caprella danilevskii. Mar. Ecol. Prog. Seri. 235, 171-176.

Ohji, M., Arai, T. and Miyazaki, N. 2003. Chronic effects of tributyltin on the caprellid amphipod Caprella danilevskii. Mar. Pollu. Bull. 46(10), 1263-1272.

Ohji, M., Takeuchi, I., Takahashi, S., Tanabe, S. and Miyazaki, N. 2002b. Differences in the acute toxicities of tributyltin between the Caprellidea and the Gammaridea (Crustacea: Amphipoda). Mar. Pollu. Bull. 44(1), 16-24.

Raff, M.C. 1992. Social controls on cell survival and cell death. Nature. 356(6368), 397-400.

Swain, G.W., Nelson, W.G. and Preedeekanit, S. 1998. The influence of biofouling adhesion and biotic disturbance on the development of fouling communities on non-toxic surfaces. Biofoul. 12(13), 257-269.

Tanguay, J.A., Reyes, R.C. and Clegg, J.S. 2004. Habitat diversity and adaptation to environmental stress in encysted embryos of the crustacean Artemia. J. Biosci. 29(4), 489-501.

Toi, H.T., Boeckx, P., Sorgeloos, P., Bossier, P. and Van Stappen, G. 2013. Bacteria contribute to Artemia nutrition in algae-limited conditions: a laboratory study. J.Aquacult. 388, 1-7.
Wang, J., Wang, Q., Li, J., Shen, Q., Wang, F. and Wang, L. 2012. Cadmium induces hydrogen peroxide production and initiates hydrogen peroxidedependent apoptosis in the gill of freshwater crab, Sinopotamon henanense. Comp. Biochem. Physiol. C Toxicol. Pharmacol. 156(3), 195-201.

WHO. 2020. International programme on chemical safety. Environmental health criteria. Available via https://www.who.int/ipcs/publications/ehc/en/ (Accessed 15 July 2020).

Yang, B., Li, L., Pu, F., You, W., Huang, H. and Ke, C. 2015. Molecular cloning of two molluscan caspases and gene functional analysis during Crassostrea angulata (Fujian oyster) larval metamorphosis. Mol. Biol. Rep. 42(5), 963-975.

Zhang, J., Zuo, Z., Chen, Y., Zhao, Y., Hu, S. and Wang, C. 2007. Effect of tributyltin on the development of ovary in female cuvier (Sebastiscus marmoratus). Aquat. Toxicol. 83(3), 174-179.

Zhou, J., Wang, W.-N., He, W.-Y., Zheng, Y., Wang, L., Xin, Y. and Wang, A.-L. 2010. Expression of HSP60 and HSP70 in white shrimp, Litopenaeus vannamei in response to bacterial challenge. J. Invert. Pathol. 103(3), 170-178.

Zuo, Z., Wu, T., Lin, M., Zhang, S., Yan, F., Yang, Z. and Wang, C. 2014. Chronic exposure to tributyltin chloride induces pancreatic islet cell apoptosis and disrupts glucose homeostasis in male mice. Environ. Sci. Technol. 48(9), 5179-5186. 